\title{
La Paradoja Medioambiental: entre el desarrollo económico y la protección al medio ambiente
}

José Félix Pinto-Bazurco Barandiarán

Abogado por la Universidad de Lima. Máster en Derecho por la Universidad de Sibiu, Rumania.

SUMARI0:

I. Introducción.

II. El Protocolo de Kioto: Un acuerdo global.

III. Los resultados de Kioto.

IV. El Caso Peruano.

V. Superar la Paradoja.

VI. Conclusión. 


\section{INTRODUCCIÓN}

Históricamente, se puede observar que para que un país llegue a tener un desarrollo económico que le permita preocuparse e invertir recursos en protección ambiental, ha tenido primero que pasar por un desarrollo industrial que ignore casi por completo la protección al medio ambiente: Europa, China y los Estados Unidos no serían las potencias que son hoy, si es que al inicio de su desarrollo industrial hubiesen concentrado tantos recursos en proteger el medio ambiente como lo hacen y como se les exige hoy en día a los países en desarrollo.

En lo que respecta a políticas medioambientales modernas, la comunidad internacional de manera paulatina, se pone de acuerdo en tratados sucesivos, que tienen su origen en convenios sobre pesquería y protección de especies desde mediados del siglo $\mathrm{XIX}^{1}$, hasta el recientemente más importante, Protocolo de Kyoto sobre el Cambio Climático ${ }^{2}$. El interés de la comunidad internacional se ve manifestado en la cantidad de acuerdos y convenciones que tratan el tema ambiental y que dan la impresión de que la protección al medio ambiente es una de las preocupaciones principales en la agenda de la gobernanza global.

Sin embargo, con las grandes diferencias económicas que aún subsisten en el planeta, el legislador y los políticos se tropiezan en lograr un consenso de reglas que puedan ser aplicadas en todo el mundo, ya que a la hora de implementar dichas políticas en la legislación interna de cada país, sigue predominado el interés por el desarrollo económico por encima de la protección al medio ambiente. Lo que resulta aplicable por ejemplo, en Alemania, no necesariamente puede ser adecuado para el Perú y a primera vista, puede crear la preocupación de que nuestros gobiernos carecen de una visión a largo plazo.

\section{EL PROTOCOLO DE KIOTO: UN ACUERDO GLOBAL}

La relación entre desarrollo económico y protección al medio ambiente es un problema que ha sido tratado por una serie de autores y científicos y que ha sido incluido en varios tratados internacionales desde finales del siglo pasado. Un ejemplo, es la Convención Marco de las Naciones Unidas sobre el Cambio Climático (UNFCCC), que se celebró en 1992 y dio lugar al Protocolo de Kioto, un acuerdo internacional que establece la meta de la comunidad internacional de reducir sus emisiones contaminantes, incluyendo las que causarían el efecto del calentamiento global. Este acuerdo, introduce una serie de mecanismos - predominantemente económicos - para lograr tal finalidad ${ }^{3}$ y que - puesto de manera simple- permiten a los países industrializados -y sus compañías- "comprar" el derecho de contaminar, convirtiendo los gases que producen el efecto invernadero en productos comercializables. Además, incorpora dos principios, que para este ensayo resultan relevantes: i) la idea de que no importa el lugar en donde se producen o reduzcan las emisiones contaminantes, ya que su efecto es a nivel global y ii) el concepto de la responsabilidad común, pero diferenciada de los Estados, que es un intento de parte de los legisladores de manifestar el hecho de que los países desarrollados han contribuido en mayor

1. Los primeros intentos de desarrollar reglas medioambientales a nivel internacional se enfocaban en la conservación de fauna y en cierta medida también, de ríos y mares. Estos se basaban en estudios hechos por renombrados científicos como Alexander von Humboldt o Henri de Saussure y trataban temas bastante específicos; pero abrieron el paso hacia tratados internacionales con contenido más amplio, como los que tenemos hoy.

2. Este Protocolo surgió como acuerdo adicional a la Convención Marco de las Naciones Unidas sobre el Cambio Climático y tiene por objetivo principal “Reducir la emisión de gases que producen el efecto invernadero que causan el calentamiento global".

3. Los llamados Mecanismos de Flexibilidad del Protocolo de Kioto son tres: i) Comercio con Bonos de Carbono (Emissions Trading) ii) Actividades de Implementación Conjunta (Joint Implementation) y iii) Mecanismo de Desarrollo Limpio (Clean Development Mechanism). 
parte a la contaminación ambiental y a su vez de considerar la necesidad de desarrollo de los países emergentes.

\section{Los Mecanismos de Flexibilidad del Protocolo} de Kioto, son creados con el fin de reducir los costos necesarios para lograr las metas de reducción de gases contaminantes (en el Protocolo, denominados Gases de Efecto Invernadero o GEI), asimismo, promueven el trabajo en cooperación entre los Estados desarrollados y en vías de desarrollo. Países como Alemania, Francia o EE.UU., que pueden establecer temas de protección al medio ambiente en agenda, trabajan, en cumplimiento con estos mecanismos, en el intercambio de temas medioambientales, preservando asimismo sus propios intereses. A pesar de esto, que parece un escenario ideal, donde los ricos y los pobres trabajan juntos por un bien mayor, es evidente - si se observan las constantes guerras, que son una de las causas más devastadoras del medio ambiente- que sigue predominando el interés por la hegemonía y el desarrollo económico por encima del interés por un medio ambiente adecuado.

\section{LOS RESULTADOS DE KIOTO}

Cuando a finales del siglo pasado, los países lograron ponerse de acuerdo y plasmar una meta de reducción de emisiones, se vivió con mucho entusiasmo lo que iba a llegar a ser el inicio de una era verde: una política global basada en principios de sostenibilidad y sentido común, en beneficio de nuestro planeta $y$, por ende, de todos sus habitantes. El día de hoy, estamos muy cerca al cumplimiento del plazo establecido en el Protocolo de Kioto (2012) y las perspectivas son oscuras. Si bien, se ha hecho mucho por reducir las emisiones contaminantes, países con economías emergentes como China, han aumentado sus emisiones ${ }^{4}$, mientras que países con altos niveles de emisiones como los Estados Unidos de América, se mantienen al margen del acuerdo.

Las últimas reuniones de las partes signatarias del UNFCCC (Ilamadas Conferencia de las Partes o (OP) han generado mucha más incertidumbre respecto al futuro de esta alianza global defensora del planeta 5 . En la reunión de Bali en 2007, las partes establecieron un plazo de dos años para elaborar un pacto que sustituya al de Kioto, no siendo capaces de ponerse de acuerdo en la reunión de Copenhagen, dos años más tarde. A fines de este año, las expectativas se enfocarán en la ciudad de Durban, en donde se realizará la próxima COP y, en donde, probablemente la Unión Europa sea la única agrupación de Estados con voluntad de llegar a un acuerdo post-Kioto, estando ya afuera del Convenio dos de los mayores emisores como son Estados Unidos y China.

\section{EL CASO PERUANO}

La necesidad de proteger el medio ambiente en el Perú se puede medir en términos económicos: un estudio ${ }^{6}$ elaborado por el Banco Central de Reserva del Perú, estima que, de no tomar medidas frente a las posibles consecuencias de un cambio en el clima - en el peor de los casos, un escenario con un aumento de temperatura de $2^{\circ} \mathrm{C}$ y $20 \%$ en la variabilidad de las precipitaciones al año 2050- las pérdidas económicas ascenderían hasta en un $20 \%$ del PBI potencial. Sin embargo, si se logran llevar a cabo medidas de mitigación y/o prevención, las pérdidas se reducirían a la mitad. Puesto de manera simple: si bien es cierto que resulta costoso invertir en la protección al medio ambiente - en el largo plazo- resulta mucho más costoso no hacerlo.

4. Las emisiones per cápita en China han aumentado desde 1990, de 2,2 toneladas al año a 6,8. Mientras tanto, la media europea es de 8,1 toneladas al año, casi la mitad de la cantidad media estadounidense, que es de 16,9 toneladas al año. Fuente: UNFCCC

5. Denominación propia del autor para conceptualizar el esfuerzo común de los países miembros del UNFCCC.

6. VARGAS, Paola. El Cambio Climático y Sus Efectos en el Perú, Banco Central de Reserva del Perú, D.T. No. 2009-14, Serie de Documentos de Trabajo, 2009. 
Los problemas medioambientales con los que tendría que lidiar el Perú en el futuro son graves: un aumento o disminución en las precipitaciones e incrementos de temperatura pueden dar lugar a inundaciones, sequías, heladas, granizados, huaycos, aludes y aluviones que de darse sin estar preparados, seguramente afectarán a la pesca, la agricultura, la generación de energía y a la sociedad en general. El derretimiento de los glaciares tropicales trae, como consecuencia directa, la falta de reservas de agua e, indirectamente, desertificación y falta de generación eléctrica (el Perú genera el $60 \%$ de su electricidad mediante centrales hidroeléctricas).

Tomando en cuenta que, el Perú es uno de los países que se verían más afectados con las consecuencias de un posible cambio climáti$\mathrm{CO}^{7}$, sería pertinente que el gobierno peruano adquiera una visión a largo plazo y ayude a generar una conciencia ciudadana basada en que la protección al medio ambiente tiene consecuencias sobre los aspectos más importantes en nuestras vidas: salud, alimentación, energía y economía.

\section{SUPERAR LA PARADOJA}

La paradoja consiste en que no es posible para un país concentrar esfuerzos en la protección del medio ambiente, si aún no cuenta con un desarrollo económico adecuado, a pesar de que es claro que tampoco es posible mantener un desarrollo económico sin contar con recursos sostenibles.

Es claro que mantener una visión cortoplacista resulta mucho más simple que tener la paciencia y la fe que se requiere para tomar decisiones a largo plazo. Una persona normal requiere de muchos años de experiencia, para entender que la recompensa es mayor cuando se espera y no se deja contentar con satisfacciones inmediatas. Lo mismo debe coincidir con la política gubernamental. Es cierto que los problemas de fragilidad dentro de los partidos políticos en el Perú, hacen muy difícil mantener políticas sostenibles a largo plazo. Sin embargo, algo que se mantiene constante son las relaciones internacionales, ya sea en términos privados o públicos, en la forma de empresas o convenios de cooperación. Estas, se mantienen vigentes más allá del plazo que ocupan los gobiernos de turno y si estas se desarrollan bajo principios de sostenibilidad y logran mantenerse sólidas, a pesar del paso esporádico de gobiernos y líderes políticos, es posible que la conciencia medioambiental en el Perú, también, crezca y se consolide como un eje fundamental.

\section{CONCLUSIÓN}

Crear un control legal sobre actividades que afectan adversamente al medio ambiente considerando que éstas son fundamentales para el desarrollo de la economía de cada Estadopuede resultar una tarea compleja. Por ello, la cooperación entre países como Perú con potencias como la U.E. y los EE.UU. es -en un principio- buena, porque les permite intercambiar experiencia y tecnología que pueden ayudar a lograr esa finalidad. Sin embargo, la política de Perú debe apuntar a poder realizar proyectos con iniciativas propias, poniendo, en primer lugar, su desarrollo nacional y sin perder de vista jamás el hecho de que los seres humanos no somos dueños del medio ambiente, sino parte de éste y que la tierra no la hemos heredado de nuestros antepasados, sino que la tomamos prestada de nuestros hijos.

7. Según datos recogidos por el Ministerio de Ambiente peruano, publicados en el "Plan de Acción y Mitigación frente al Cambio Climático" publicado por el MINAM en 2010. 